Mots. Les langages du politique

$114 \mid 2017$

Le rapport, entre description et recommandation

\title{
Marianne Doury, Argumentation : analyser textes et discours
}

Paris, A. Colin, 2016, 191 p.

Chloé Gaboriaux

\section{OpenEdition}

\section{Journals}

Édition électronique

URL : https://journals.openedition.org/mots/22871

DOI : $10.4000 /$ mots.22871

ISSN : 1960-6001

Éditeur

ENS Éditions

Édition imprimée

Date de publication : 10 juillet 2017

Pagination : 209-210

ISSN : 0243-6450

Référence électronique

Chloé Gaboriaux, « Marianne Doury, Argumentation : analyser textes et discours », Mots. Les langages du politique [En ligne], 114 | 2017, mis en ligne le 20 juin 2017, consulté le 24 avril 2022. URL : http:// journals.openedition.org/mots/22871; DOI : https://doi.org/10.4000/mots.22871

Ce document a été généré automatiquement le 24 avril 2022

(C) ENS Éditions 


\title{
Marianne Doury, Argumentation: analyser textes et discours
}

Paris, A. Colin, 2016, 191 p.

\author{
Chloé Gaboriaux
}

\section{RÉFÉRENCE}

DOURY M., Argumentation : analyser textes et discours, Paris, A. Colin, 2016, 191 p.

1 Avec ce manuel, Marianne Doury donne aux étudiants de tous niveaux les moyens d'analyser les divers discours argumentatifs auxquels ils sont confrontés. Après avoir situé sa démarche, descriptive et langagière, parmi les diverses approches de l'argumentation (chapitre 1), elle en aborde les principaux points d'entrée : énonciation (chapitre 2), contre-discours (chapitre 3), types d'arguments (chapitre 4), rhétorique (chapitre 5) et marqueurs langagiers de l'argumentation (chapitre 6). Sont également disponibles en ligne un chapitre complémentaire consacré à la structure de l'argumentation ${ }^{1}$ ainsi qu'un glossaire ${ }^{2}$ et une bibliographie ${ }^{3}$ bien utiles, qu'il est dommage de ne pas avoir intégrés à l'ouvrage. Le propos est d'une grande clarté, illustré par des encadrés consacrés aux notions-clés et par des exemples et exercices corrigés qui permettent de maîtriser progressivement les catégories d'analyse des sciences du langage en matière d'argumentation mais aussi de la rhétorique moderne (types de preuves et d'arguments, par exemple).

2 L'auteure insiste sur la variété des discours argumentatifs, de l'échange quotidien à la discussion scientifique en passant par le débat de café du commerce. À cet égard, l'illustration de couverture (Karl Anton Hickel, William Pitt, Premier ministre de la Grande Bretagne, s'adressant à la Chambre des communes) est trompeuse : les discours politiques institutionnels sont rares parmi les exemples, qui témoignent d'une préférence marquée pour les argumentaires ordinaires, entendus dans la rue ou repris aux médias, décelés dans une affiche publicitaire ou, plus rarement, reconstruits pour la démonstration. Choisis avec intelligence et humour, ces derniers contribuent à rendre 
la lecture agréable et intéresseront sans doute les étudiants à qui le livre est destiné : souvent peu accoutumés à repérer les stratégies argumentatives des discours qu'ils rencontrent quotidiennement, ils auront certainement plaisir à les voir décryptées ici.

Le souci d'expliciter régulièrement le caractère descriptif de l'approche retenue dans ce manuel rencontre en outre de façon très heureuse les exigences auxquelles sont plus particulièrement confrontés les étudiants qui s'engagent dans un cursus en sciences sociales: contre les habitudes prises dans l'enseignement secondaire, où l'étude de l'argumentation est toujours peu ou prou l'occasion d'apprendre à prendre position, ils sont désormais invités à distinguer nettement ce qui relève du descriptif et du normatif. Dans cette perspective, certains chapitres - et en particulier celui sur la rhétorique - auraient peut-être gagné à clarifier le statut des emprunts aux analyses normatives visant à jauger l'efficacité des procédés langagiers employés pour argumenter.

4 Revendiqué dans un ouvrage destiné aux jeunes adultes que sont nos étudiants, un tel positionnement ne saurait en effet se réduire à un principe scientifique, fût-il fondamental. Suspendre momentanément le jugement, se décentrer pour saisir les intentions argumentatives d'autrui, repérer un point de vue à travers un choix lexical ou une construction syntaxique, n'est-ce pas aussi ce que devrait apprendre tout citoyen en devenir? Il s'agit moins alors d'évaluer les argumentations en lutte que de se mettre en mesure non seulement d'en saisir les ressorts, mais aussi et surtout d'admettre le caractère relatif des vérités politiques et morales, qui ouvre à la délibération démocratique (Perelman et Olbrechts-Tyteca, 1958). Dans ce moment historique paradoxal qui répond à la résurgence des dogmatismes par l'absurdité de la politique contrefactuelle (post-truth politics), enseigner l'argumentation, c'est se placer délibérément du côté du pluralisme et des raisons défendables.

\section{NOTES}

1. < http://medias.dunod.com/document/9782200613310/Doury_Argumentation-Chapitre supplementaire.pdf> (consulté le 6 juin 2017).

2. < http://medias.dunod.com/document/9782200613310/Doury-Argumentarion-glossaire.pdf> (consulté le 6 juin 2017).

3. <http://medias.dunod.com/document/9782200613310/Doury-Argumentation-Pour-aller-plusloin.pdf> (consulté le 6 juin 2017). 


\section{AUTEURS}

\section{CHLOÉ GABORIAUX}

Sciences Po Lyon, Triangle 